\title{
The Effect of Ginger Hydroalcholic Extract on Rat Ileal Contraction in Vitro
}

\author{
Ahmad Ali Jalali-Nezhad, ${ }^{1}$ Farzaneh Farajian-Mashhadi, ${ }^{2}$ Gholamreza Komeili,, ${ }^{,}$and Farzaneh \\ Barkhordari-Ahmadi ${ }^{1}$ \\ ${ }^{1}$ Department of Physiology, Faculty of Medicine, Zahedan University of Medical Sciences, Zahedan, IR Iran \\ ${ }^{2}$ Department of Pharmacology, Faculty of Medicine, Zahedan University of Medical Sciences, Zahedan, IR Iran \\ "Corresponding author: Gholamreza Komeili, Department of Physiology, Faculty of Medicine, Zahedan University of Medical Sciences, Zahedan, IR Iran. E-mail: \\ rkomeili@gmail.com
}

Received 2015 January 22; Accepted 2015 April 30.

\begin{abstract}
Background: Ginger is a medicinal plant with wide use around the world which has several therapeutic implications especially in gastrointestinal discomfort such as dyspepsia, flatulence, colic, diarrhea, nausea and vomiting.

Objectives: Therefore, given the widespread use of ginger for the treatment of gastrointestinal diseases, in the present study we have investigated the effect of this herbal medicine and underlying mechanism on pre-contracted rat ileum segments.

Materials and Methods: In this experimental study, 40 male rat divided to 5 groups ( $n=8$ in each group) randomly. Groups were consisting: ginger alone, $\mathrm{KCl}+$ ginger, carbachol + ginger, pretreated with L-NAME and $\mathrm{KCl}+$ ginger, pretreated with verapamil and $\mathrm{KCl}+$ ginger. To investigate the mechanism underlying relaxation induced by ginger extract on rat ileum, isolated rat ileum segments were pre-contracted by $\mathrm{KCl} 120 \mu \mathrm{mol}$ or carbachol $100 \mu \mathrm{mol}$ and then relaxation response induced by ginger hydroalcholic extracts (with 100 or $200 \mu \mathrm{g} / \mathrm{mL}$ of organ bath) was studied in the presence of verapamil (a calcium channel blocker agents) and L-NAME (a nitric oxide synthase inhibitor).

Results: Non-cumulative concentrations of ginger extract (100 and $200 \mu \mathrm{g} / \mathrm{mL}$ ) was able to decrease contractile responses to $\mathrm{KCl}$ $(120 \mu \mathrm{mol} / \mathrm{mL}$ of organ bath) and carbachol $(100 \mu \mathrm{mol} / \mathrm{mL}$ of organ bath $)$ in a dose dependent manner $(\mathrm{P}<0.05)$. Incubation of tissue with L-NAME (300 $\mu \mathrm{mol} / \mathrm{mL})$ was not able to reduce the relaxation response; however incubation with verapamil inhibited the relaxation response induced by ginger extract.

Conclusions: The relaxation response induced by ginger extract in the present study was not mediated by nitric oxide. However calcium channel may contribute to relaxation response.
\end{abstract}

Keywords: Ginger, Ileal Motility, Rat

\section{Background}

The rhizome of Zingiber officinale Rosecoe (ginger) which known as a food spice was a herbal medicine used around the world for centuries. Gingerols (i.e. 6-gingerol, 8-gingerol and zingerone) have been recognized as the main active ingredients of ginger, which is accountable for its pungent taste. Other constituents include volatile oil, aryl alkanes, shogaols, diarylheptanoids and starch [1]. Different therapeutic effects of this plant reported previously. Several studies showed various pharmacological effects of this compound including anticancer [2], anxiolytic [3], anti-inflammatory [4], antithrombotic [5], hypoglycemic and hypolipidemic [6] effects. Ginger also plays a major role in gastrointestinal tract such as cholagogic effect [7], anti-inflammatory [8], antineoplastic [9, 10] antihelicobacter pillory, anti-emetic and prokinetic [11-15] effects. In digestive tract, it has been demonstrated that ginger extract abolished the chemotherapy induced delay in gastric emptying in rats [16] and also it reduced nausea associated with motion sickness [17]. Moreover in rat colon it has been shown that ginger extract decrease motility [18]. While in the rat ileum it has spasmolytic effect [19], in guinea pig ileum ginger improves motility [20]. Isolated gingerols and shogaols have been shown to modify gastric motility in animal experiments [21]. Although it was demonstrated that ginger accelerated gastric motility [12], about lower gastrointestinal region there are paradoxical information [18-20]. It seems that the effect of ginger in gastrointestinal tract motility, depends to organ and spices and different in upper and lower part of gastrointestinal tract. On the other hands, changes induced in small intestine motility, can affect on this function. Despite of different reports about the pharmacological effects of ginger in human and animal studies, there are few reports of ginger effect on ileum motility and underlying mechanism in literature. 


\section{Objectives}

Therefore, given the widespread use of ginger for the treatment of gastrointestinal diseases, in the present study we have investigated the effect of this herbal medicine and underlying mechanism on pre-contracted rat ileum segments.

\section{Materials and Methods}

\subsection{Preparation of Extract}

In this experimental study, the rhizome of ginger, for the proposed work was obtained from local herbal stores in Zahedan and identified with herbarium of Sistan and Baluchistan university. The whole plant material was dried under shade and mechanically reduced to powder and stored in air tight containers for further use in extraction process. The ginger powder was successively extracted using soxhlet apparatus with methanol 70\% (1 to 4 portions) as solvent. The extracts were dried in incubator at $37^{\circ} \mathrm{C}$. The dried methanolic extract was dissolved in saline solution for further experiments in 100 or $200 \mu \mathrm{g} / \mathrm{mL}$ of organ bath.

\subsection{Animals}

Forty male Wistar albino rats (Zahedan university strain)(220 - $250 \mathrm{~g}$ ) were maintained under controlled conditions of temperature $\left(22-24^{\circ} \mathrm{C}\right)$ and 12 hour of dark and light cycle until used and divided in five groups randomly ( $\mathrm{n}=8$ in each group). Groups were consisting: ginger alone (100 and $200 \mu \mathrm{g} / \mathrm{mL}), \mathrm{KCl}+$ ginger (100 and $200 \mu \mathrm{g} / \mathrm{mL}$ ), carbachol $(100 \mu \mathrm{mol} / \mathrm{mL})+\operatorname{ginger}(200 \mu \mathrm{g} / \mathrm{mL})$, pretreated with L-NAME (300 $\mu \mathrm{mol} / \mathrm{mL})$ and $\mathrm{KCl}+\operatorname{ginger}(200 \mu \mathrm{g} / \mathrm{mL})$, pretreated with verapamil $(100 \mu \mathrm{mol} / \mathrm{mL})$ and $\mathrm{KCl}+$ ginger $(200 \mu \mathrm{g} / \mathrm{mL})$. The rats had free access to water and food. All procedures were carried out in accordance with Zahedan University of Medical Sciences guidelines for animal care. Animals were killed by decapitation and the whole intestine was removed and immediately placed in freshly prepared Tyrode's solution (composition $\mathrm{mM}: \mathrm{NaCl}=136.9, \mathrm{KCl}$ $=2.68, \mathrm{MgCl}_{2}=1.05, \mathrm{CaCl}_{2}=1.8, \mathrm{NaHCO}_{3}=11.9$ and glucose $=5.55)$ at room temperature. The mesentery and fatty tissue were removed and the intestine was emptied of its contents by flushing Tyrode's solution. Two centimeter long segments taken from the ileum was connected vertically to a tissue holder by cotton threads and to isometric transducer ML T0 50/D. The tissues were bathed in a $25 \mathrm{~mL}$ waterjacketed organ bath containing $20 \mathrm{~mL}$ Tyrode's solution and placed under $0.5 \mathrm{~g}$ tension. The Tyrode's solution was maintained at a temperature of $37 \pm 0.5^{\circ} \mathrm{C}$. Each tissue was left to equilibrate for 1 hour and washed every 15 minutes. Longitudinally-mediated responses were recorded using isometric transducer ML T0 50/D and displayed, stored and analyzed in a PC Pentium computer using Power Lab Chart V4.0.4 software. Each experiment was repeated for 8 times, using fresh tissues. Therefore, for each part of experiment 8 animals have been used. The final concentrations of ginger extract were 100 and $200 \mu \mathrm{g} / \mathrm{mL}$ in organ bath. After a minimal 60 minutes equilibration period the tissues were subjected to $\mathrm{KCl} 120 \mu \mathrm{mol} / \mathrm{mL}$. After stable control contractions by $\mathrm{KCl}$ had been recorded, the responses were observed in the presence of ginger (100 and $200 \mu \mathrm{g} / \mathrm{mL}$ ).

The contact time for each concentration of ginger was 10 minutes. Preliminary experiments showed that ginger reached its maximal inhibitory effect within this time period. In some experiments, the effect of verapamil (100 $\mu \mathrm{mol} / \mathrm{mL}$ ), a calcium channel blocker, on $\mathrm{KCl}$ induced contractions was evaluated. The effect of ginger was also evaluated after the administration in the bath (contact time 30 minutes $)$ of verapamil $(100 \mu \mathrm{mol} / \mathrm{mL})$ and NG-nitro-Larginine methyl ester (L-NAME $300 \mu \mathrm{mol} / \mathrm{mL}$ ) (to block NO synthesis). In preliminary experiments the effect of atropine $(1 \mu \mathrm{mol} / \mathrm{mL})$ on $\mathrm{KCl}$ induced contractions was evaluated after a contact time of 30 minutes. The effect of ginger was also evaluated on the contractions produced by carbachol $(100 \mu \mathrm{mol} / \mathrm{mL})$. This concentration of carbachol gave a contractile response which was similar in amplitude to that obtained by $\mathrm{KCl}$.

\subsection{Drugs}

Atropine, carbachol, L-NAME and verapamil were purchased from Sigma (UK), KCl and other reagents were obtained from Merck company (Germany). Ginger methanolic extract was dissolved in saline solution. The other drugs were dissolved in distilled water.

\subsection{Analysis of Results}

Current investigation was an experimental study, based on changes in $\mathrm{g}$ tension of isolated tissues to $\mathrm{KCl}$ before and after different treatments. The tension was expressed as the percentage of the maximal response to $\mathrm{KCl} \pm$ standard error of means (SEM). The significance of differences was determined by ANOVA statistical test, using SPSS-17 software. Values less than 0.05 were considered statistically significant.

\section{Results}

4.1. The Effect of Ginger Extract on Contractile Response Induced by $\mathrm{KCl}$ and Carbachol

Non-cumulative concentrations of ginger extract (100 and $200 \mu \mathrm{g} / \mathrm{mL})$ significantly decreased $(\mathrm{P}=0.027)$ the contractile response induced by $\mathrm{KCl}(120 \mu \mathrm{mol})$ in a dose de- 
pendent manner (Figures 1 and 2). In Figure 1 representative trace showing that injection of $200 \mu \mathrm{g} / \mathrm{mL}$ ginger extract induced a small contraction $(0.1 \mathrm{~g})$ followed by significant relaxation ( $2 \mathrm{~g}$ ). According to Figure 2, this reduction in contractile response has been significantly increased by elevating of ginger concentration. Moreover, contractile response induced by carbachol (a cholinergic agonist) 100 $\mu$ mol significantly reduced to $60 \%$ in the presence of ginger extract (Figure 3).

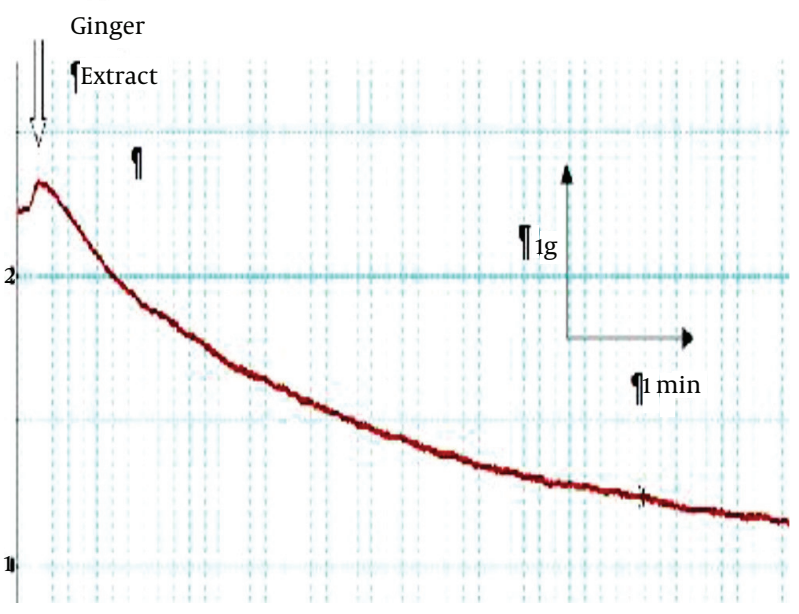

Figure 1. Representative tracing of initial contraction and Subsequent Relaxation Response of Ginger Extract $200 \mu \mathrm{mol}$ in Tissues Pre-Contracted by KCl $120 \mu \mathrm{mol} / \mathrm{mL}$ Taken From the Rat Ileum

Figure 2. The Contraction Responses Induced by $\mathrm{KCl} 120 \mu \mathrm{mol} / \mathrm{mL}$ in the Absence and Presence of Ginger Extract (100 and $200 \mu \mathrm{g} / \mathrm{mL}$ ) in the Rat Ileum

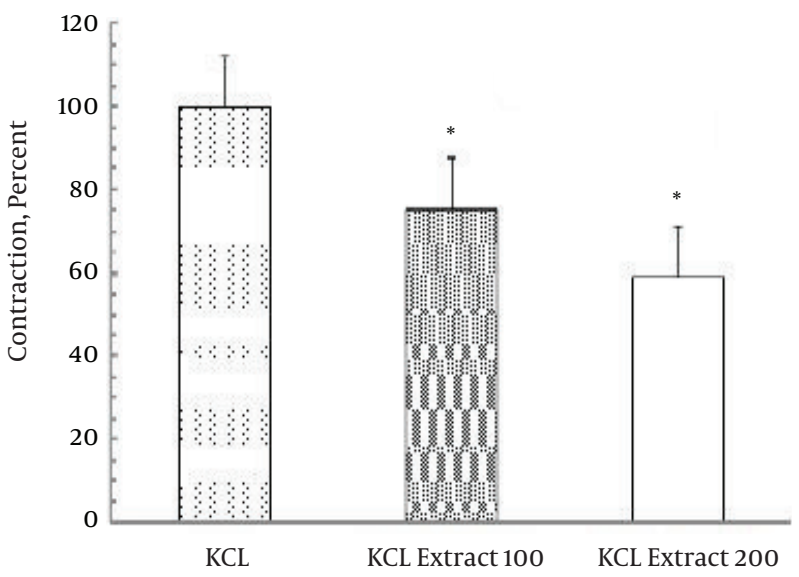

Each point represents the mean $\pm \mathrm{SEM} ; \mathrm{n}=8 ;{ }^{*} \mathrm{P}=0.027$ taken as significant difference compared to the $\mathrm{KCl}$ values.
Figure 3. The Contraction Responses Induced by Carbachol $100 \mu \mathrm{mol} / \mathrm{mL}$ in the absence and Presence of Ginger Extract $(200 \mu \mathrm{g} / \mathrm{mL})$ in the Rat Ileum

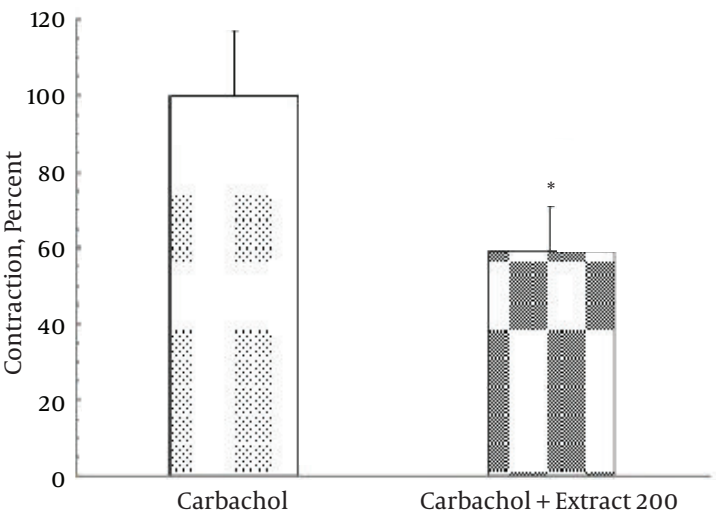

Each point represents the mean $\pm S E M ; n=8 ;{ }^{*} \mathrm{P}=0.02$ taken as significant difference compared to the carbachol values.

4.2. The Effect of L-NAME on Relaxation Induced by Ginger Extract on Pre-Contracted Tissues

Incubation of ileal tissues by L-NAME $300 \mu \mathrm{M}$, a nitric oxide synthase inhibitor failed to modify the contractile response induced by $\mathrm{KCl}$ alone and in the presence of ginger extract $(200 \mu \mathrm{g} / \mathrm{mL})$ (Figure 4$)$.

Figure 4. The Contraction Responses Induced by $\mathrm{KCl} 120 \mu \mathrm{mol} / \mathrm{mL}$ in the Absence and Presence of Ginger Extract $(200 \mu \mathrm{M})$ and L-NAME in the Rat Ileum

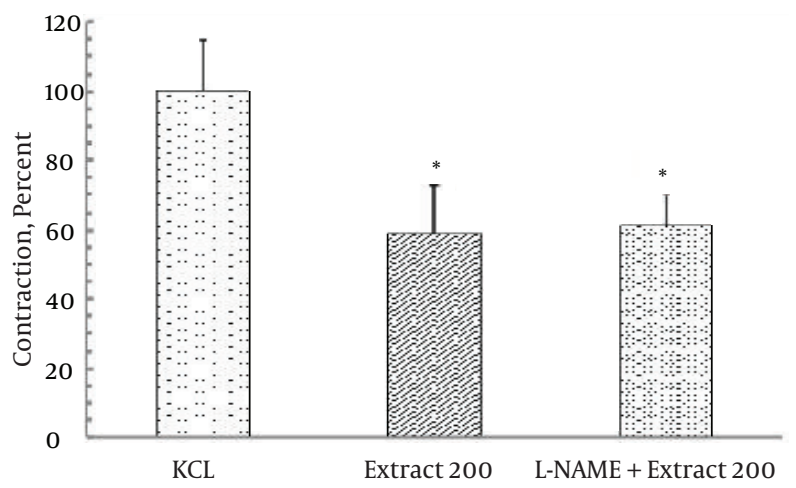

Each point represents the mean \pm SEM; $\mathrm{n}=8 ;{ }^{*} \mathrm{P}=0.015$ taken as significant difference compared to the $\mathrm{KCl}$ values.

\subsection{The Effect of Verapamil on Contractile Response to KCl in the Presence of Ginger Extract}

In the presence of verapamil the $\mathrm{KCl}$ contractile response decreased by 50\% but not abolished. Moreover in the presence of verapamil, ginger extract failed to modify the contractile response to $\mathrm{KCl}$ (Figure 5). 
Figure 5. The Contraction Responses Induced by $\mathrm{KCl} 120 \mu \mathrm{mol} / \mathrm{mL}$ in the Absence and Presence of Ginger Extract $(200 \mu \mathrm{g} / \mathrm{mL})$ and Verapamil in the Rat Ileum

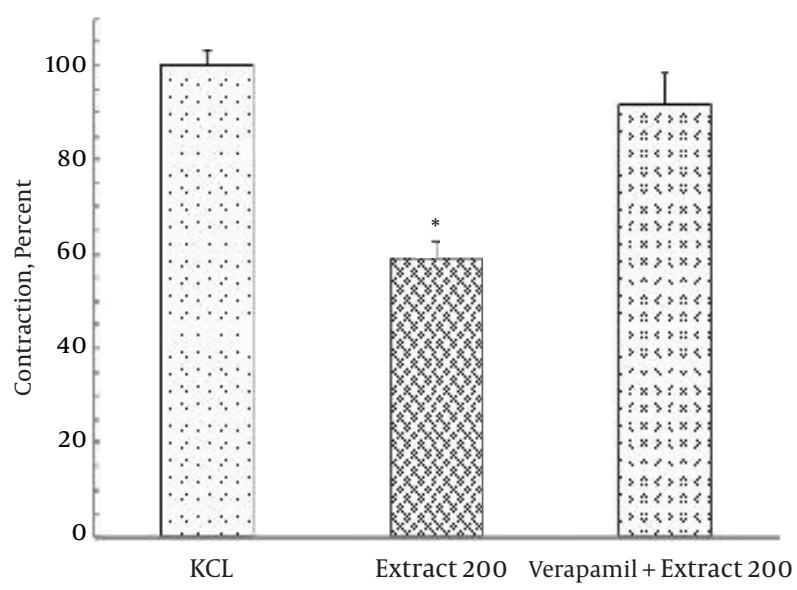

Each point represents the mean $\pm S E M ; n=8 ; * P=0.03$ taken as significant difference compared to the $\mathrm{KCl}$ values.

\section{Discussion}

In present study, it was shown that hyrdoalcholic extract of ginger is capable to reduce the contractile response to $\mathrm{KCl}$ and carbachol which indicates a relaxation response. This relaxation response do not inhibit with LNAME. Thus this relaxatory effect of ginger not mediated with nitric oxide. Also, these results shown that ginger extract can to reduce the contraction induced with carbachol in rat ileal smooth muscle.

Effects of ginger on the gastrointestinal motility were widely reported $[15,16,20]$. It was demonstrated that ginger accelerated gastric motility such as emptying and antral contractions in healthy volunteers and in patients with functional dyspepsia [12]. However about lower gastrointestinal region there are controversial reports [18-20]. In line with present study, Borrelli et al. demonstrated that ginger could inhibit both electrical field stimulation (EFS) and acetylcholine-evoked contractions [22]. However, another study presented that even single dose of ginger dried root was able to increase carbachol-induced small intestinal transit [20]. Borrelli et al. concluded that ginger possesses both prejunctional and postjunctional inhibitory effects on rat ileal contractility; the prejunctional inhibitory effect of ginger on enteric excitatory transmission could involve a capsazepine-sensible site which could be vanilloid receptors [22]. However they pre-contracted rat ileum by electrical field stimulation which makes different experimental condition. Furthermore in current study relaxation response induced by ginger extract was insensitive to L-NAME, NO synthase inhibitor. This indicates that relaxation response was not mediated by nitric oxide pathway which is the most important inhibitory neurotransmission in gastrointestinal tract [23]. To find out mechanism underlying relaxation response, the mode of relaxation of verapamil, an L-type calcium channel blocker was compared with ginger extract which showed similar trend and also in the presence of verapamil, ginger extract failed to attenuate the contractile response to $\mathrm{KCl}$. It was already shown that the predominant source of $\mathrm{Ca}^{2+}$ for the contractile response is extracellular $\mathrm{Ca}^{2+}$ and intracellular $\mathrm{Ca}^{2+}$ has little role to play in mediating excitation-contraction coupling in rat distal colon smooth muscle in vitro [24].

In 2006, Kong et al. demonstrated that verapamil, significantly attenuated, but did not completely eliminate the high $\mathrm{K}^{+}$- and ACh-induced contraction, indicating that additional channels might be involved in the contractile mechanism. They concluded that contraction of smooth muscle in the distal colon is regulated by multiple $\mathrm{Ca}^{2+}$ channels. In addition to voltage-operated $\mathrm{Ca}^{2+}$ channel -mediated $\mathrm{Ca}^{2+}$ influx, store-operated $\mathrm{Ca}^{2+}$ channels participates in contractile response of distal colon smooth muscle in rats [25]. In conclusion, present study showed that ginger hyrdoalcholic extract have inhibitory effect on contractile response induced by either carbachol or $\mathrm{KCl}$. However this relaxation response could not be mediated by nitric oxide. Furthermore, disappearing of relaxation response in presence of verapamil indicates that voltage gated L-type calcium channel might mediate the ginger relaxation response on pre-contracted ileal tissues.

Results of this study shown that hydroalcholic extract of ginger can decrease contraction induced with $\mathrm{KCl}$ and carbachol in rat ileal muscle and nitric oxide has no any involvement in this effect. Further experiment using electrophysiological study is necessary to investigate the exact role played by $\mathrm{Ca}^{2+}$ channels in rat ileum or other mechanism involved in relaxation response induced by ginger.

\section{Acknowledgments}

We are grateful to research department of Zahedan University of Medical Sciences for their financial support. The number of this dissertation was 5875. The Authors thank the physiology laboratory technicians for their help and also animals house personnel's.

\section{Footnote}

Funding/Support: Zahedan University of Medical Sciences. 


\section{References}

1. Butt MS, Sultan MT. Ginger and its health claims: molecular aspects. Crit Rev Food Sci Nutr. 2011;51(5):383-93. doi: 10.1080/10408391003624848. [PubMed: 21491265].

2. Gundala SR, Mukkavilli R, Yang C, Yadav P, Tandon V, Vangala S, et al. Enterohepatic recirculation of bioactive ginger phytochemicals is associated with enhanced tumor growth-inhibitory activity of ginger extract. Carcinogenesis. 2014;35(6):1320-9. doi: 10.1093/carcin/bgu011. [PubMed: 24431413].

3. Nievergelt A, Huonker P, Schoop R, Altmann KH, Gertsch J. Identification of serotonin 5-HT1A receptor partial agonists in ginger. Bioorg Med Chem. 2010;18(9):3345-51. doi: 10.1016/j.bmc.2010.02.062. [PubMed: 20363635].

4. Mashhadi NS, Ghiasvand R, Askari G, Hariri M, Darvishi L, Mofid MR. Anti-oxidative and anti-inflammatory effects of ginger in health and physical activity: review of current evidence. Int J Prev Med. 2013;4(Suppl 1):S36-42. [PubMed: 23717767].

5. Thomson M, Al-Qattan KK, Al-Sawan SM, Alnaqeeb MA, Khan I, Ali $M$. The use of ginger (Zingiber officinale Rosc.) as a potential antiinflammatory and antithrombotic agent. Prostaglandins Leukot Essent Fatty Acids. 2002;67(6):475-8. [PubMed: 12468270].

6. Arablou T, Aryaeian N, Valizadeh M, Sharifi F, Hosseini A, Djalali M. The effect of ginger consumption on glycemic status, lipid profile and some inflammatory markers in patients with type 2 diabetes mellitus. Int J Food Sci Nutr. 2014;65(4):515-20. doi: 10.3109/09637486.2014.880671. [PubMed: 24490949].

7. Yamahara J, Miki K, Chisaka T, Sawada T, Fujimura H, Tomimatsu T, et al. Cholagogic effect of ginger and its active constituents. J Ethnopharmacol. 1985;13(2):217-25. [PubMed: 4021519].

8. Ho SC, Chang KS, Lin CC. Anti-neuroinflammatory capacity of fresh ginger is attributed mainly to 10-gingerol. Food Chem. 2013;141(3):3183-91. doi: 10.1016/j.foodchem.2013.06.010. [PubMed: 23871076].

9. Citronberg J, Bostick R, Ahearn T, Turgeon DK, Ruffin MT, Djuric Z, et al. Effects of ginger supplementation on cell-cycle biomarkers in the normal-appearing colonic mucosa of patients at increased risk for colorectal cancer: results from a pilot, randomized, and controlled trial. Cancer Prev Res (Phila). 2013;6(4):271-81. doi: 10.1158/19406207.CAPR-12-0327. [PubMed: 23303903].

10. Deol PK, Kaur IP. Improving the therapeutic efficiency of ginger extract for treatment of colon cancer using a suitably designed multiparticulate system. J Drug Target. 2013;21(9):855-65. doi: 10.3109/1061186X.2013.829076. [PubMed: 23962278].

11. Palatty PL, Haniadka R, Valder B, Arora R, Baliga MS. Ginger in the prevention of nausea and vomiting: a review. Crit Rev Food Sci Nutr. 2013;53(7):659-69. doi: 10.1080/10408398.2011.553751. [PubMed: 23638927].

12. Hu ML, Rayner CK, Wu KL, Chuah SK, Tai WC, Chou YP, et al. Effect of ginger on gastric motility and symptoms of functional dyspepsia. World
J Gastroenterol. 2011;17(1):105-10. doi: 10.3748/wjg.v17.i1.105. [PubMed: 21218090].

13. Shariatpanahi ZV, Taleban FA, Mokhtari M, Shahbazi S. Ginger extract reduces delayed gastric emptying and nosocomial pneumonia in adult respiratory distress syndrome patients hospitalized in an intensive care unit. J Crit Care. 2010;25(4):647-50. doi: 10.1016/j.jcrc.2009.12.008. [PubMed: 20149584].

14. Wu KL, Rayner CK, Chuah SK, Changchien CS, Lu SN, Chiu YC, et al. Effects of ginger on gastric emptying and motility in healthy humans. Eur J Gastroenterol Hepatol. 2008;20(5):436-40. doi: 10.1097/MEG.0b013e3282f4b224. [PubMed: 18403946].

15. Yamahara J, Huang QR, Li YH, Xu L, Fujimura H. Gastrointestinal motility enhancing effect of ginger and its active constituents. Chem Pharm Bull (Tokyo). 1990;38(2):430-1. [PubMed: 2337957].

16. Sharma SS, Gupta YK. Reversal of cisplatin-induced delay in gastric emptying in rats by ginger (Zingiber officinale). J Ethnopharmacol. 1998;62(1):49-55. [PubMed: 9720611].

17. Lien HC, Sun WM, Chen YH, Kim H, Hasler W, Owyang C. Effects of ginger on motion sickness and gastric slow-wave dysrhythmias induced by circular vection. Am J Physiol Gastrointest Liver Physiol. 2003;284(3):G481-9. doi: 10.1152/ajpgi.00164.2002. [PubMed: 12576305].

18. Iwami M, Shiina T, Hirayama H, Shimizu Y. Intraluminal administration of zingerol, a non-pungent analogue of zingerone, inhibits colonic motility in rats. Biomed Res. 2011;32(2):181-5. [PubMed: 21551955]

19. Riyazi A, Hensel A, Bauer K, Geissler N, Schaaf S, Verspohl EJ. The effect of the volatile oil from ginger rhizomes (Zingiber officinale), its fractions and isolated compounds on the 5-HT3 receptor complex and the serotoninergic system of the rat ileum. Planta Med. 2007;73(4):355-62. doi: 10.1055/s-2007-967171. [PubMed: 17511060].

20. Satoh K, Kase Y, Hayakawa T, Murata P, Ishige A, Sasaki H. Dai-kenchuto enhances accelerated small intestinal movement. Biol Pharm Bull. 2001;24(10):1122-6. [PubMed: 11642315].

21. Pertz HH, Lehmann J, Roth-Ehrang R, Elz S. Effects of ginger constituents on the gastrointestinal tract: role of cholinergic M3 and serotonergic 5-HT3 and 5-HT4 receptors. Planta Med. 2011;77(10):9738. doi:10.1055/s-0030-1270747. [PubMed: 21305447].

22. Borrelli F, Capasso R, Pinto A, Izzo AA. Inhibitory effect of ginger (Zingiber officinale) on rat ileal motility in vitro. Life Sci. 2004;74(23):2889-96. doi: 10.1016/j.lfs.2003.10.023. [PubMed: 15050426].

23. Brookes SJ. Neuronal nitric oxide in the gut. J Gastroenterol Hepatol. 1993;8(6):590-603. [PubMed: 7506586].

24. Zhou H, Kong DH, Pan QW, Wang HH. Sources of calcium in agonistinduced contraction of rat distal colon smooth muscle in vitro. World J Gastroenterol. 2008;14(7):1077-83. [PubMed: 18286690].

25. Kong DH, Zhou H, Song J, Ke DP, Hu JL, Li ZW, et al. [Capacitative $\mathrm{Ca}(2)(+)$ entry is involved in ACh-induced distal colon smooth muscle contraction in rats]. Sheng Li Xue Bao. 2006;58(2):149-56. [PubMed: 16628362]. 